\title{
Reduced Irradiation Time in Slow-curing of Resin Composite Using an Intensity- changeable Light Source
}

\author{
Tomoko $\mathrm{ABO}^{1, *}$, Shigeru $\mathrm{UNO}^{2}$ and Junji TAGAMI ${ }^{1}$ \\ ${ }^{1}$ Section of Cariology and Operative Dentistry, Department of Restorative Sciences, Division of Oral Health Sciences, Gradu- \\ ate School, Tokyo Medical and Dental University, 1-5-45 Yushima, Bunkyo-ku, 113-8549, Tokyo, Japan \\ ${ }^{2}$ Department of Dentistry, Toranomon Hospital, 2-2-2 Toranomon, Minato-ku, 105-8570, Tokyo, Japan \\ ${ }^{*}$ Corresponding author, E-mail:abo.ope@tmd.ac.jp
}

Received February 1, 2005/Accepted March 18, 2005

\begin{abstract}
Possibility to shorten the total irradiation time in slow-curing with an intensity-changeable light source, Curetron 7 (CT-7), was investigated for four hybrid-type resin composites. Irradiation condition with CT-7 was assigned as 10 or 20 seconds at low light intensity $\left(230 \mathrm{~mW} / \mathrm{cm}^{2}\right)$ and followed by 20 or 10 seconds at high intensity $\left(600 \mathrm{~mW} / \mathrm{cm}^{2}\right)$ respectively $(i . e$, a total of 30 seconds). For a reference, irradiation was carried out for 30 seconds using a halogen lamp $\left(900 \mathrm{~mW} / \mathrm{cm}^{2}\right)$. After irradiation, mechanical properties of the cured composites - in terms of microhardness and flexural strength - were evaluated. Also, cavity adaptation was examined in standardized, cylindrical dentin cavities treated with an adhesive system. Compared to the reference irradiation, slow-curing with CT-7 produced acceptable mechanical properties and better adaptation. These results suggested that total exposure time of slow-curing with CT-7 could be shortened to 30 seconds.
\end{abstract}

Key words: Resin composite, Slow-curing, Polymerization

\section{INTRODUCTION}

General practitioners place a special emphasis on shortening treatment time. Curing time for resin composites is no exception, and several light curing units (LCUs) have been developed for this purpose. Currently, several types of LCU are available: conventional quartz-tungsten-halogen lamp (QTH), plasma-arc curing unit (PAC), light amplification by stimulated emission of radiation (LASER), and lightemitting diode $(\mathrm{LED})^{1}$. Each LCU has different intensity, spectral output, and curing mode.

Polymerization shrinkage of resin composites, which occurs during irradiation, often causes unpleasant post-operation symptoms ${ }^{2,3)}$. Against this background, various attempts have been made to lessen contraction stress, e.g., sandwich technique, incremental filling technique, and usage of flowable resin composite ${ }^{3-7)}$. Curing mode also has an effect on contraction stress reduction, and one of the effective methods is the so-called slow-curing technique. A lot of studies have shown that this technique reduces gap formation and produces good mechanical properties (or degree of conversion) in cured resin composites $^{8-17)}$.

Uno et $a l^{14)}$ devised a QTH LCU for slow-curing, Curetron 7 (CT-7; Osada Electric Industry, Tokyo, Japan). CT-7 is a hand-piece type light source (a light window of $10 \mathrm{~mm}$ in diameter) connected to the dental chair. The output spectrum of CT-7 has a sharp and single peak around $480 \mathrm{~nm}$, and light intensity is changeable from the lowest $230 \mathrm{~mW} / \mathrm{cm}^{2}$ to the highest $600 \mathrm{~mW} / \mathrm{cm}^{2}$. Their study proved the efficacy of slow-curing method when an interval was inserted between two irradiation conditions of low intensity and high intensity. However, total curing time was 50 seconds - longer than the time that practitioners expect. A shorter irradiation time will better enable the light guide to be maintained at the best curing position during light irradiation.

Therefore, the purpose of this study was to confirm if irradiation time in slow-curing could be shortened using CT-7. The hypothesis was that a total irradiation time of 30 seconds would be good enough to produce good cavity adaptation and acceptable mechanical properties in cured composites.

\section{MATERIALS AND METHODS}

Four hybrid-type resin composites and a self-etching priming system were used in this study (Table 1). Two curing light sources were used under four selected irradiation conditions (Table 2). The light intensity of each condition was monitored with a radiometer (Curing Radiometer Model 100; Demetron Kerr, Danbury, CT, USA) during the experiment.

\section{Surface microhardness}

Resin composite (Table 1) was filled into a cylindrical acrylic mold $(3 \mathrm{~mm}$ in diameter $\times 2 \mathrm{~mm}$ in height) as a bulk. Having covered both sides with transparent strips and compressed with glass plates by hands, the composite was light-cured from one side with three different irradiation conditions: OP30, L20-H10, and L10-H20 (Table 2). Immediately after irradiation, the specimen was placed on the stage of 
Table 1 Materials used in this study

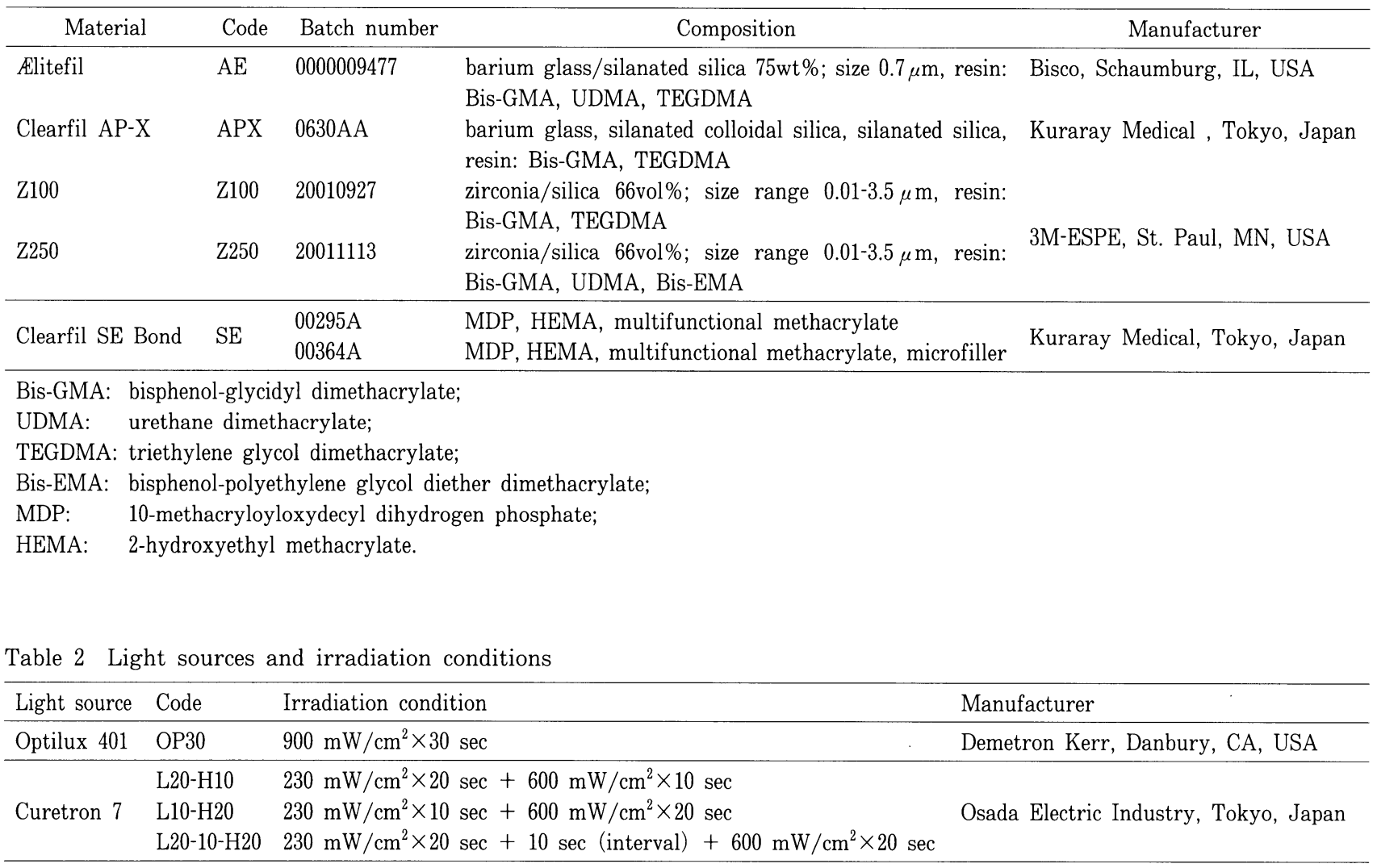

a microhardness indentation tester (MZT-4; Akashi, Tokyo, Japan) to measure microhardness at both top and bottom surfaces (Fig. 1). The indentation technique employed in this study used a cone-shaped indentor $\left(68^{\circ}\right)$, and hardness was calculated from the following formula: HUT [68] $=\mathrm{K} \times$ main load/(indentation depth $)^{2}$, where $\mathrm{K}$ is a coefficient. Indentations were carried out under a preload at $0.0002 \mathrm{~N}$ and main load at $0.01 \mathrm{~N}$ for 30 seconds, first at the bottom surface and then at the top surface. Six specimens were prepared for each irradiation condi-
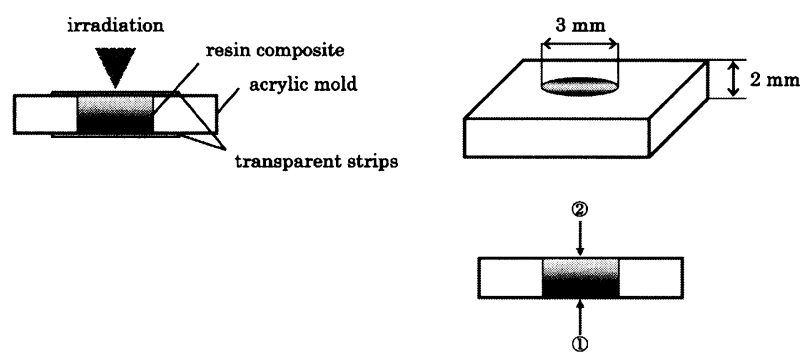

Fig. 1 Schematic diagram of microhardness measurement. Each specimen was measured at (1) bottom surface and (2) top surface, immediately after irradiation. Measurements were carried out at five points on each surface. Indentation method (AKASHI MZT4, Tokyo, Japan). tion/composite combination, and indentation was carried out at five random points on each surface. All measurements were done within five minutes for each specimen. Finally, mean value and standard deviation were calculated for each material.

\section{Flexural strength}

Resin composite was filled into an acrylic mold (2.5 $\mathrm{mm}$ in thickness $\times 5.5 \mathrm{~mm}$ in width $\times 18.0 \mathrm{~mm}$ in length). Having covered both sides with transparent strips, the composite was compressed with glass plates by hands. Light irradiation was carried out three times on each side: first at the center and then at $1 / 3$ from each end of the specimen. Four irradiation conditions - OP30, L20-H10, L10-H20, and L2010-H20 (Table 2) - were conducted. The condition of L20-10-H20 was tested for a reference since Uno et $a l{ }^{14)}$ reported on good curing performance with this condition. After each condition, the irradiated specimen was gently removed from the mold and stored at $37^{\circ} \mathrm{C}$ for 24 hours. Then, the specimen was polished with \# $1000 \mathrm{SiC}$ paper. Following which, threepoint bending test was performed to measure flexural strength at a cross-head speed of $1.0 \mathrm{~mm} / \mathrm{min}$ in a universal testing machine (Instron Model 8500; High Wycombe, UK) (Fig. 2). Six specimens were prepared for each irradiation condition/composite combination, and the mean value and standard 


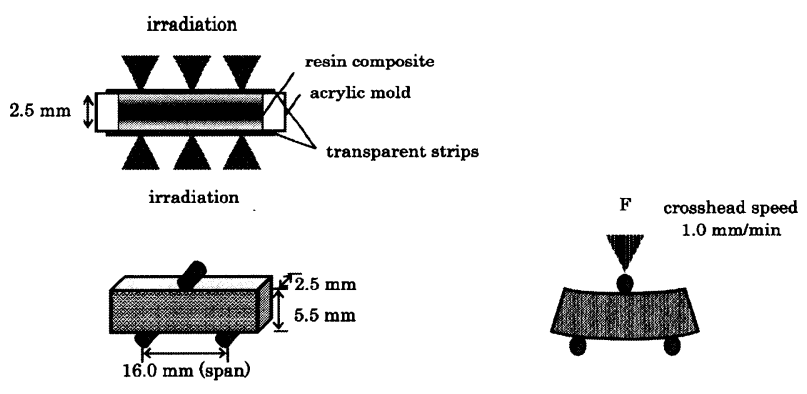

Fig. 2 Schematic diagram of flexural strength measurement. All specimens were measured after storage at $37^{\circ} \mathrm{C}$ for 24 hours. Three-point bending test (INSTRON Model 8500).

deviation were calculated for each material.

\section{Cavity adaptation}

Extracted human molars stored in $0.5 \mathrm{w} / \mathrm{w} \%$ chloramine- $\mathrm{T}$ solution were used in this study. Buccal surface of the tooth was ground with \#600 $\mathrm{SiC}$ paper under running water until a flat dentin surface was exposed, and a cylindrical dentine cavity $(3.0 \mathrm{~mm}$ in diameter $\times 1.5 \mathrm{~mm}$ in depth) was prepared thereby. The cavity was treated with a selfetching priming adhesive system according to manufacturer's instructions, and filled with one of the four resin composites as a bulk (Table 1). After being covered with transparent strips, the resin composite was light-cured under one of the four different irradiation conditions: OP30, L20-H10, L10-H20, or L20-10-H20 (Table 2). The condition of L20-10-H20 was also tested, as described for flexural strength measurement. Excess material was immediately removed by gently wet grinding with \#1000 to \#1500 $\mathrm{SiC}$ paper until the margin was exposed. After marginal adaptation was evaluated under an incident microscope (BX60M; Olympus, Tokyo, Japan) at $\times 500$ magnification, the tooth was embedded in epoxy resin. The specimen was longitudinally sectioned with a low-speed saw (Isomet; Buehler, IL, USA) at the center of the restoration. Wall adaptation was evaluated at seven points on each surface of the sec-
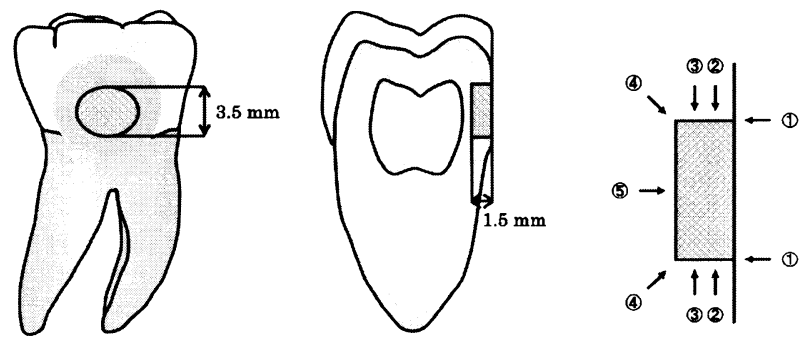

Fig. 3 Evaluation of cavity adaptation. Observation points were: (1) top surface; (2) outer $1 / 3$; (3) inner $1 / 3$; (4) line angle; and (5) cavity floor. tion - outer $1 / 3$, inner $1 / 3$, line angle, and cavity floor - under the incident microscope (Fig. 3). If a gap was found between the cavity wall and composite, the maximum gap width would be recorded at each observation point. Six specimens were prepared for each irradiation condition/composite combination.

\section{Statistical analyses}

Microhardness was analyzed with three- and two-way ANOVA and Scheffe's test at 5\% level of significance. Flexural strength of resin composite surfaces was examined with two-way ANOVA and Scheffe's test. Cavity adaptation was assessed using Kruskal-Wallis and Mann-Whitney U-test at 5\% level of significance.

\section{RESULTS}

\section{Surface microhardness}

Microhardness results for each irradiation condition were given in Table 3. Three-way ANOVA - which analyzed the effects of irradiation condition, material, and measured surface on microhardness - revealed the interaction between surface and material $(p<0.05)$. For each material, two-way ANOVA showed no interactions between irradiation condition and measured surface $(p>0.05)$. In Table $4-1$, it was found that irradiation condition had no influence on microhardness. In Table 4-2, it was shown that measured surface had a significant effect on microhardness. When comparing microhardness between top and bottom surfaces, the following irradiation condition/composite combinations showed no significant differences: OP30 for all materials; L10$\mathrm{H} 20$ for Z100; and L20-H10 and L10-H20 for APX (Scheffe, $p>0.05$ ). In other groups, the top surface was harder than the bottom one $(p<0.05)$.

\section{Flexural strength}

Flexural strength results for each irradiation condi-

Table 3 Microhardness (HUT/68) of cured composite surfaces

\begin{tabular}{llcc}
\hline Condition & Composite & Top surface & Bottom surface \\
\hline OP30 & AE & $26(4.4)$ & $22(6.7)$ \\
& APX & $34(7.0)$ & $32(4.7)$ \\
& Z100 & $32(2.9)$ & $29(3.8)$ \\
& Z250 & $27(3.9)$ & $26(4.2)$ \\
\hline L20-H10 & AE & $23(2.6)$ & $16(2.7)$ \\
& APX & $35(5.0)$ & $33(3.3)$ \\
& Z100 & $31(2.3)$ & $29(3.1)$ \\
& Z250 & $30(3.5)$ & $24(2.6)$ \\
\hline L10-H20 & AE & $23(2.1)$ & $17(2.4)$ \\
& APX & $33(7.0)$ & $30(4.7)$ \\
& Z100 & $28(4.1)$ & $28(3.7)$ \\
& Z250 & $28(3.4)$ & $24(4.1)$ \\
\hline
\end{tabular}

Mean (S.D.) is given $(n=5)$. 
Table 4-1 Comparison of microhardness (HUT/68) among irradiation conditions for each material

\begin{tabular}{llll}
\hline Composite & OP30 & L20-H10 & L10-H20 \\
\hline AE & & \\
APX & & \\
Z100 & & \\
Z250 & & & \\
\end{tabular}

Horizontal line denotes no significant differences $(\mathrm{p}=0.05)$.

Table 4-2 Comparison of microhardness (HUT/68) among between top and bottom surfaces for each material

\begin{tabular}{lccc}
\hline Composite & OP30 & L20-H10 & L10-H20 \\
\hline AE & - & $\bigcirc$ & $\bigcirc$ \\
APX & - & - & - \\
Z100 & - & $\bigcirc$ & - \\
Z250 & - & $\bigcirc$ & $\bigcirc$ \\
\hline
\end{tabular}

$\bigcirc$ : significant difference;

- : not significant difference $(p=0.05)$.

tion are given in Table 5. Two-way ANOVA revealed independent influence of both irradiation condition and material. The strength of Alitefil was significantly lower than those of the other three materials in all conditions (Scheffe, $\mathrm{p}<0.05$ ). When comparing irradiation conditions, L20-H10 and L10-H20 produced equal strength as OP30 for all materials (Scheffe, $\mathrm{p}>0.05$ ) (Table 6). Furthermore, L10-H20 and L20-10-H20 showed higher strength than L20-H10 $(\mathrm{p}>0.05)$.

\section{Cavity adaptation}

Table 7 shows the respective gap formation measurements for each irradiation condition/material group.
Table 5 Flexural strength of cured composites

\begin{tabular}{lll}
\hline Condition & Composite & \multicolumn{1}{c}{$\mathrm{MPa}$} \\
\hline OP30 & AE & $178(5.0)$ \\
& APX & $205(25)$ \\
& Z100 & $197(21)$ \\
& Z250 & $203(16)$ \\
\hline L20-H10 & AE & $147(11)$ \\
& APX & $184(17)$ \\
& Z100 & $195(6.2)$ \\
Z250 & $206(27)$ \\
\hline \multirow{2}{*}{ L10-H20 } & AE & $168(8.3)$ \\
& APX & $209(21)$ \\
& Z100 & $194(12)$ \\
L20-10-H20 & Z250 & $230(7.0)$ \\
\hline & AE & $157(24)$ \\
& APX & $211(17)$ \\
& Z100 & $185(26)$ \\
& & $237(7.4)$ \\
\hline
\end{tabular}

Mean (S.D.) is given $(n=5)$.

Table 6 Comparison of flexural strength among the irradiation conditions

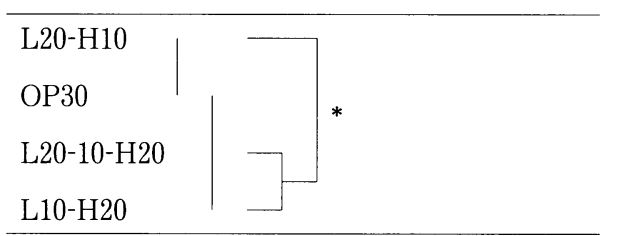

Vertical lines denote no significant differences $(\mathrm{p}>0.05)$.

Asterisk denotes a difference between irradiation conditions connected $(\mathrm{p}<0.05)$.

Table 7 Cavity adaptation

\begin{tabular}{lllccccc}
\hline Condition & Composite & top surface & outer $1 / 3$ & inner $1 / 3$ & line angle \\
\hline OP30 & AE & $0,0,0,2,4,4$ & $0,0,0,0,0,0$ & $0,0,0,1,1,10$ & $0,0,1,3,8,12$ & $0,8,8,10,14,18$ \\
& APX & $0,0,0,1,2,2$ & $0,0,0,0,0,0$ & $0,0,0,0,0,1$ & $0,0,0,0,0,0$ & $0,0,1,2,4,6$ \\
& Z100 & $0,1,1,2,6,7$ & $0,0,0,0,1,5$ & $0,0,0,1,2,4$ & $0,0,0,0,1,2$ & $0,0,0,0,0,1$ \\
& Z250 & $0,0,0,0,0,1$ & $0,0,0,0,0,0$ & $0,0,0,0,0,2$ & $0,0,0,1,1,2$ & $0,0,0,0,1,1$ \\
\hline \multirow{2}{*}{ L20-H10 } & AE & $0,0,2,2,3,4$ & $0,0,0,0,0,2$ & $0,0,0,0,10,12$ & $0,0,0,0,10,10$ & $0,0,2,6,10,10$ \\
& APX & $0,0,0,0,0,0$ & $0,0,0,0,0,0$ & $0,0,0,0,0,10$ & $0,0,0,0,1,4$ & $0,0,0,4,4,14$ \\
& Z100 & $0,0,0,0,4,6$ & $0,0,0,0,4,6$ & $0,0,0,4,4,6$ & $0,0,0,0,2,2$ & $0,0,2,2,3,4$ \\
& Z250 & $0,0,0,0,0,1$ & $0,0,0,0,0,1$ & $0,0,0,0,0,0$ & $0,0,0,0,0,1$ & $0,0,0,0,0,0$ \\
\hline \multirow{2}{*}{ L10-H20 } & AE & $0,0,0,1,1,3$ & $0,0,0,0,0,0$ & $0,0,0,0,0,4$ & $0,0,0,0,0,3$ & $0,0,0,0,0,2$ \\
& APX & $0,0,0,0,0,0$ & $0,0,0,0,0,0$ & $0,0,0,0,2,3$ & $0,0,0,0,1,4$ & $0,0,0,0,0,2$ \\
& Z100 & $0,0,0,0,0,4$ & $0,0,0,0,0,4$ & $0,0,0,0,4,8$ & $0,0,0,0,1,6$ & $0,2,2,3,3,11$ \\
& Z250 & $0,0,0,0,0,0$ & $0,0,0,0,0,0$ & $0,0,0,0,0,0$ & $0,0,0,0,0,1$ & $0,0,0,0,0,0$ \\
\hline \multirow{2}{*}{ L20-10-H20 } & AE & $0,0,0,0,0,0$ & $0,0,0,0,0,0$ & $0,0,0,0,0,0$ & $0,0,0,0,0,1$ & $0,0,0,0,0,3$ \\
& APX & $0,0,0,0,0,0$ & $0,0,0,0,0,0$ & $0,0,0,0,0,0$ & $0,0,0,0,1,2$ & $0,0,0,0,0,0$ \\
& Z100 & $0,0,0,0,2,2$ & $0,0,0,0,0,3$ & $0,0,0,0,3,4$ & $0,0,1,1,2,3$ & $0,0,0,0,1,3$ \\
& Z250 & $0,0,0,0,2,2$ & $0,0,0,0,0,3$ & $0,0,0,0,3,4$ & $0,0,1,1,2,3$ & $0,0,0,0,1,3$ \\
\hline
\end{tabular}

Maximum gap width $(\mu \mathrm{m})$ at the measurement points $(\mathrm{n}=6)$. 
Table 8 Comparison of cavity adaptation among the irradiation conditions

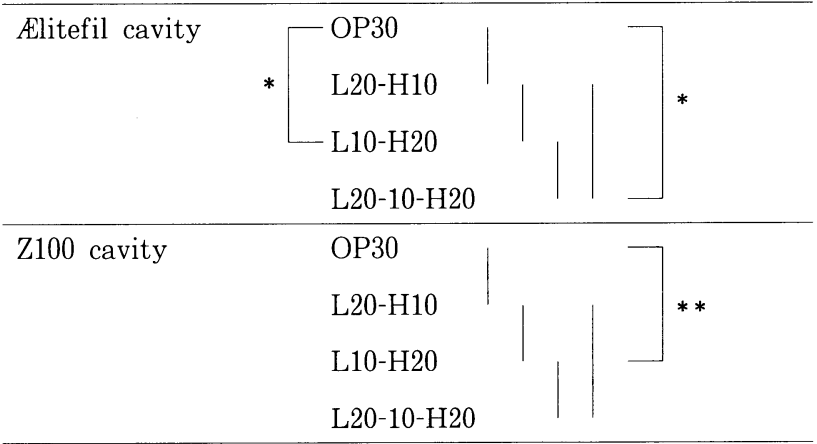

Vertical lines denote no significant differences $(p>0.05)$. Asterisk denotes a difference between irradiation conditions connected $(\mathrm{p}<0.05)$.

For each group, adaptation differed significantly at top surface and cavity floor among the measurement points (Kruskal-Wallis, $\mathrm{p}<0.05$ ). Moreover for Alitefil and Z100, there were significant differences among the irradiation conditions (Mann-Whitney, $\mathrm{p}<0.05)$. L10-H20 and L20-10-H20 for Ælitefil and L10-H20 for Z100 showed significantly better adaptation than OP30 $(\mathrm{p}>0.05)$ (Table 8).

\section{DISCUSSION}

Polymerization shrinkage is a major drawback of resin composite restorations. When a composite is bonded to the cavity wall, polymerization shrinkage generates a stress at the bonding interface according to its quantification (volumetric and linear shrinkage), phase (pre-gel, post-gel, and total shrinkage), and distribution (uniform and non-uniform shrinkage $)^{6)}$. Shrinkage stress is a property-complex, which means it is affected by multiple material properties (polymerization contraction and modulus development), geometry, and boundary conditions ${ }^{6)}$. Indeed, a lot of studies showed that contraction stress was associated with elastic modulus and degree of conversion of the composite, and also with cavity adaptation $^{17-26)}$. Sakaguchi et al. ${ }^{27)}$ found that polymerization contraction force rate was linearly correlated to irradiance. In this vein, it is very important to perform slow-curing with a low light intensity at the pre-gel stage of the composite to reduce contraction stress ${ }^{11)}$. An argument against this slow-curing approach is that low light intensity likely results in poor conversion of the composite. One solution is the two-step curing method. Composites irradiated with higher light intensity followed by low intensity have shown good mechanical properties and better cavity adaptation ${ }^{8,9,13,14,23)}$. However, in clinical situations, a shorter irradiation time is more desirable for both clinician and patient.

This study sought to verify whether total expo- sure time could be shortened to 30 seconds. In terms of microhardness, there were no significant differences among the three irradiation conditions: OP30, L20-H10, and L10-H20. In terms of flexural strength, no differences were found between $\mathrm{L} 20-\mathrm{H} 10$ and OP30, and among OP30, L20-10-H20, and L10-H20. These results implied that $\mathrm{L} 20-\mathrm{H} 10$ and $\mathrm{L} 10-\mathrm{H} 20$, though only of 30 seconds' total exposure time, produced favorable mechanical properties. Regarding cavity adaptation in Ælitefil and Z100, L20-10-H20 produced the best adaptation among the conditions tested. This concurred with the result of Uno et $a l .{ }^{14)}$. Further, compatible good adaptation was generated by $\mathrm{L} 10-\mathrm{H} 20$ rather than $\mathrm{L} 20-\mathrm{H} 10$ for these two composites.

Energy density $\left(\mathrm{J} / \mathrm{cm}^{2}\right)$ is expressed as a value: power density $\left(\mathrm{W} / \mathrm{cm}^{2}\right) \times$ exposure time (seconds) ${ }^{28)}$. Vandewalle et al. ${ }^{29)}$ showed that energy density and degree of conversion had significant influence on gingival marginal defects, but not on microleakage. Of interest is that total energy densities of $\mathrm{L} 20-\mathrm{H} 10$ and L10-H20 were $10.6 \mathrm{~J} / \mathrm{cm}^{2}$ and $14.3 \mathrm{~J} / \mathrm{cm}^{2}$ respectively, which were lower than OP30 $\left(27.0 \mathrm{~J} / \mathrm{cm}^{2}\right)$ and L20-10$\mathrm{H} 20 \quad\left(16.6 \mathrm{~J} / \mathrm{cm}^{2}\right)$. In particular, reduced energy density seemed to be advantageous for cavity adaptation. In this study, we did not measure degree of conversion. However, considering the results of microhardness and flexural strength, the two irradiation conditions with lower energy density enabled the composites to be properly polymerized. Hofmann et $a l .{ }^{15)}$ demonstrated that soft-start halogen irradiation protocols succeeded in reducing the speed of contraction while maintaining an acceptable degree of cure.

For Alitefil and Z250 in this study, hardness at the bottom surface of 2 -mm thick specimen was lower than that at the top surface, when the condition of L20-H10 or L10-H20 was conducted. Tanaka et $a l .^{30)}$ measured the light intensity transmitted through cured resin composites, and reported that Alitefil transmitted light poorly as compared to other commercialized hybrid-type composites. When composite is of a certain thickness, mechanical properties at the bottom of the bulk may be related to the light intensity transmitted. In other words, the contents of monomers and fillers - as well as shades - are crucial factors that determine the polymerization of composites. Z250 is similar in composition to Z100, except for monomer Bis-EMA. But, it is not clear if the difference in microhardness between Z250 and Z100 could be attributed to Bis-EMA. Nevertheless, each material might have an optimal irradiation condition required for better curing performance of the composite $^{15,31)}$.

CT-7 has a narrow output spectrum, which is very close to LED LCU. The narrow band with a peak LED emission correctly activates camphorquinone (absorption maximum at $468 \mathrm{~nm}$ ), leading to free radical polymerization reaction. How- 
ever, for other photoinitiators in a resin composite, the so-called co-initiators have different absorption ranges (absorption maximum at $410 \mathrm{~nm}$ ), and thus LED emission may fail to activate them for polymerization $^{32,33)}$. Therefore, a careful selection of resin composite is emphatically necessary when a LED is used as the light source ${ }^{33-35}$. In general, compatibility between light spectrum and photoinitiation system should be considered not only for LED, but also for other LCUs.

Our hypothesis that total irradiation time of 30 seconds might be good enough to produce good cavity adaptation and acceptable mechanical properties in cured composites was totally confirmed. In particular, the condition of L10-H20 generated equivalent mechanical properties as OP30, and even better cavity adaptation than OP30. However, flexural strength and cavity adaptation were partially affected by the characteristics of the materials used. In conclusion, it was possible to reduce exposure time when CT-7 was used for slow-curing of resin composite restorations.

\section{ACKNOWLEDGEMENTS}

Osada Electric Industry, Tokyo, Japan, supported part of this study. The authors would like to thank Prof. Erik Asmussen (Department of Dental Materials, School of Dentistry, University of Copenhagen) for his kind suggestions and advice.

\section{REFERENCES}

1) Burgess JO, Walker RS, Porche CJ, Rappold AJ. Light curing - An update. Compend Contin Educ Dent 2002; 23: 889-906.

2) Bausch RJ. Clinical significance of polymerization shrinkage of composite resin. J Prosthet Dent 1982; 48: 59-67.

3) Davidson CL, Feilzer AJ. Polymerization shrinkage and polymerization shrinkage stress in polymer based restoratives. J Dent 1997; 25: 435-440.

4) Uno S, Shimokobe H. Contraction stress and marginal adaptation of composite restorations in dentinal cavity. Dent Mater J 1994; 13: 19-24.

5) Bowen RL, Marjenhoff WA. Dental composites/glass ionomers: The materials. Adv Dent Res 1992; 6: 44-49.

6) Versluis A, Tantbirojn D. Theoretical considerations of contraction stress. Compend Contin Educ Dent 1999; 20 (Suppl): 24-32.

7) Kugel G, Perry R. Direct composite resins: An update. Compend Contin Educ Dent 2002; 23: 593-606.

8) Uno S, Asmussen E. Marginal adaptation of a restorative resin polymerized at reduced rate. Scand J Dent Res 1991; 99: 440-444.

9) Mehl A, Hickel R, Kunzelmann KH. Physical properties and gap formation of light-cured composites with and without 'soft-start-polymerization'. J Dent 1997; 25: $321-330$.
10) Kanka III J, Suh BI. Pulse activation: reducing resinbased composite contraction stresses at the enamel cavosurface margins. Am J Dent 1999; 12: 107-112.

11) Watts $\mathrm{DC}, \mathrm{Al}$ Hindi $\mathrm{A}$. Intrinsic 'soft-start' polymerization shrinkage-kinetics in an acrylate-based resincomposite. Dent Mater 1999; 15: 39-45.

12) Sahafi A, Peutzfeldt A, Asmussen E. Soft-start polymerization and marginal gap formation in vitro. Am J Dent 2001; 14: 145-147.

13) Yoshikawa T, Burrow MF, Tagami J. A light curing method for improving marginal sealing and cavity wall adaptation of resin composite restorations. Dent Mater 2001; 17: 359-366.

14) Uno S, Tanaka $T$, Natsuizaka A, Abo T. Effect of slow-curing on cavity wall adaptation using a new intensity-changeable light source. Dent Mater 2003; 19: 147-152.

15) Hofmann N, Denner W, Hugo B, Klaiber B. The influence of plasma arc vs. halogen standard or soft-start irradiation on polymerization shrinkage kinetics of polymer matrix composites. J Dent 2003; 31: 383-393.

16) Rahiotis C, Kakaboura A, Loukidis M, Vougiouklakis G. Curing efficiency of various types of light-curing units. Eur J Oral Sci 2004; 112: 89-94.

17) Bayindir YZ, Yildiz M, Bayindir F. The effect of 'softstart polymerization' on surface hardness of two packable composites. Dent Mater J 2003; 22: 610-616.

18) Braem $M$, Lambrechts $P$, Vanherle G, Davidson CL. Stiffness increase during the setting of dental composite resins. J Dent Res 1987; 66: 1713-1716.

19) Emami N, Söderholm KJM, Berglund LA. Effect of light power density variations on bulk curing properties of dental composites. J Dent 2003; 31: 189-196.

20) Asmussen E, Peutzfeldt A. Two-step curing: influence on conversion and softening of a dental polymer. Dent Mater 2003; 19: 466-470.

21) Chen HY, Manhart J, Hickel R, Kunzelmann KH. Polymerization contraction stress in light-cured packable composite resins. Dent Mater 2001; 17: 253-259.

22) Braga RR, Ferracane JL. Contraction stress related to degree of conversion and reaction kinetics. J Dent Res 2002; 81: 114-118.

23) Lim BS, Ferracane JL, Sakaguchi RL, Condon JR. Reduction of polymerization contraction stress for dental composites by two-step light-activation. Dent Mater 2002; 18: 436-444.

24) Yoshikawa T, Burrow MF, Tagami J. The effects of bonding system and light curing method on reducing stress of different C-factor cavities. J Adhes Dent 2001; 3: $177-183$.

25) Luo Y, Lo ECM, Wei SHY, Tay FR. Comparison of pulse activation vs. conventional light-curing on marginal adaptation of a compomer conditioned using a total-etch or a self-etch technique. Dent Mater 2002; 18: $36-48$.

26) Cho BH, Dickens $\mathrm{SH}$, Bae JH, Chang CG, Son HH, Um CM. Effect of interfacial bond quality on the direction of polymerization shrinkage flow in resin composite restorations. Oper Dent 2002; 27: 297-304.

27) Sakaguchi RL, Wiltbank BD, Murchison CF. 
Contraction force rate of polymer composites is linearly correlated with irradiance. Dent Mater 2004; 20: 402-407.

28) Suh BI. Controlling and understanding the polymerization shrinkage-induced stresses in light-cured composites. Compend Contin Educ Dent 1999; 20(Suppl): 3441.

29) Vandewalle KS, Ferracane JL, Hilton TJ, Erickson RL, Sakaguchi RL. Effect of energy density on properties and marginal integrity of posterior resin composite restorations. Dent Mater 2004; 20: 96-106.

30) Tanaka $T$, Uno $S$, Ikeda $T$, Ominato $R$, Sano H. Intensity of the light transmitted through resin composites at irradiation with a variable-intensity light source. Hokkaido J Dent Sci 2000; 21: 110-117.

31) Suh BI, Cripe CA, Yin R. Light intensity and exposure time effects on light-cured composites. J Dent Res 1998; 77: 641, Abstr No. 73.

32) Park YJ, Chae KH, Rawls HR. Development of a new photoinitiation system for dental light-cure composite resins. Dent Mater 1999; 15: 120-127.

33) Uhl A, Sigusch BW, Jandt KD. Second generation LEDs for polymerization of oral biomaterials. Dent Mater 2004; 20: 80-87.

34) Hofmann N, Hugo B, Klaiber B. Effect of irradiation type (LED or QTH) on photo-activated composite shrinkage strain kinetics, temperature rise, and hardness. Eur J Oral Sci 2002; 110: 471-479.

35) Asmussen E, Peutzfeldt A. Light-emitting diode curing: Influence on selected properties of resin composites. Quintessence Int 2003; 34: 71-75. 